\title{
Research on the Rationality of the Theory of Constitution of Crimes and Its Adherence to the System of Criminal Law in China
}

\author{
Chen Xuanchi \\ People's Public Security University of China, Beijing, China, 100038
}

Keywords: Criminal constitution theory; rationality; criminal law

\begin{abstract}
In recent years, there has been a voice in the academic circles that has questioned the theory of Chinese criminal law. Some criminal law scholars believe that the theory of criminal constitution in Chinese criminal law needs to be "completely cleaned up"; the Chinese criminal law system needs to be taught according to German and Japanese criminal law, and the three-tiered crime theory system "removed and rebuilt". How do you view the constitutional criticism of crime? How to correctly evaluate the current Chinese criminal law system and the traditional criminal law theory? This paper combines personal thinking and these issues to provide reference.
\end{abstract}

\section{Rationality of the theory of criminal constitution}

\subsection{Historical rationality of the theory of criminal constitution}

The formation of the theory of criminal constitution is a historical choice, with historical inevitability. At the same time, the theory of criminal constitution has withstood the test of history and has historical rationality. In the 1950s, at the beginning of the founding of New China, Russia was the teacher and took the Soviet Union. This was the political decision of the party and the state at that time. A large number of Soviet experts came to China to teach criminal law theory. At that time, I began to study socialist criminal law with the former Soviet criminal jurist Bestlova. Under the historical conditions of the time, during the Kuomintang period, the progressive three-level criminal theory system, which was based on German and Japanese criminal law, was abolished with the old legal system. The former Soviet experts taught the completeness of the socialist countries. Different crime constitutes theory. One new and one old, one is the theoretical creation of socialist criminal law, one is the product of capitalist criminal law, the contrast is distinct, the political color is also very distinct and there is no choice in the new Chinese criminal law. China's theory of criminal constitution does come from the Soviet Union, but this kind of learning has historical inevitability and is the only inevitable choice under certain historical conditions. With the criminal constitution theory as the core, the new Chinese criminal law system has been established. The first few textbooks such as the "Principles of the Criminal Law of the People's Republic of China" in 1957 focused on the theory of criminal constitution. It is particularly worth mentioning that the Criminal Law published by the Law Press in 1982, as the first textbook of criminal law in New 
China, almost gathered the wisdom of all the important criminal jurists in the Chinese criminal law community. At the time, everyone agreed that the theory of criminal law in China should be based on the theory of criminal constitution ${ }^{[1]}$. The rationality of the theory of criminal constitution, as shown in Figure 1.

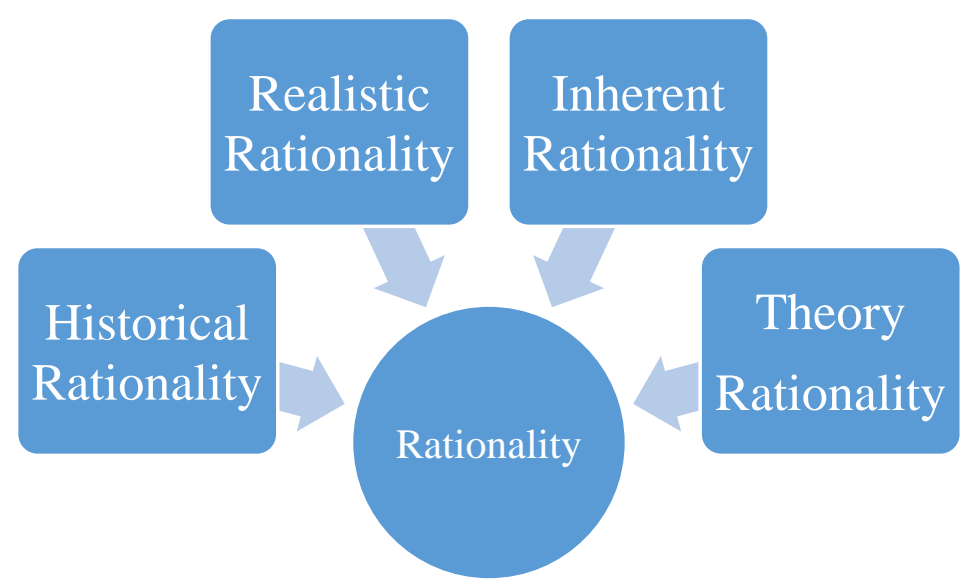

Figure 1 Rationality of the theory of criminal constitution

\subsection{The realistic rationality of the theory of criminal constitution}

The reason why the theory of criminal constitution has strong vitality is not only because it has sufficient historical inevitability, but also because it has obvious realistic rationality. China is taking the socialist road. We are building a socialist country with Chinese characteristics. From this, we decided that our legal theory must also be a legal theory with distinctive socialist characteristics. From a more specific situation, one of the more important reasons why the theory of criminal constitution has realistic rationality is that China does not have the historical tradition of civil law or common law. The Chinese criminal law system centered on the theory of criminal constitution has been established for decades and is deeply rooted in the hearts of the people. Although the German-Japanese criminal jurisprudence in the civil law system was briefly disseminated during the Republic of China, it soon disappeared with the founding of the new China. The British and American criminal law laws were not even spread in China. There has been a major impact in history. Only the core Chinese criminal law system, with the vigorous development of legal education, has taken root and spread widely ${ }^{[2]}$.

\subsection{The inherent rationality of the theory of criminal constitution}

It can be seen from the study inside the theory of criminal constitution that the theory of criminal constitution has the inherent rationality of logic, rigorous understanding and the nature of crime. It can be said that the theory of criminal constitution is not the product of impulsiveness under specific political conditions without legal basis, but the theoretical essence formed by careful thinking and repeated argumentation. Its exquisiteness is comparable to any criminal system in the world. The theory of criminal constitution is composed of four elements: the object of crime, the objective aspect of crime, the subject of crime and the subjective aspect of crime. Under the four major elements, they also include specific components. For example, the objective aspects of crime include hazard behavior, hazard results, causality, etc., based on the specific circumstances of each criminal act, the elements of crime are different from the essential elements and selective elements. The elements of the elements are composed and the elements are coupled together. The internal logic of the whole crime constitutes a very strict logic and the level of the hierarchy is quite clear. It 
properly implements a criminal behavior from coarse to fine, from the inside and out and from the whole to the part. Return to the overall analysis. At the same time, the theory of criminal constitution is also in line with people's rules of understanding ${ }^{[3]}$. Although there are different views on how the four elements are arranged, no matter what kind of viewpoints, the fact that the four elements of the object, the objective aspect, the subject and the subjective aspect are not arbitrary, but follows certain rules. I have always adhered to the traditional arrangement of object, objective aspect, subject and subjective aspect. I always think that this arrangement is accurate ${ }^{[4]}$.

It has indeed followed the rules of people's understanding. After a criminal act occurs, people first realize that "people are killed" and "property is stolen." This is the problem that reveals the object of crime. Then, the question people have to think about is how people are killed and how the property is stolen; who killed the person and who stole the property. This involves the objective aspects of crime and the subject of crime. Of course, after the criminals were discovered or captured, people should further examine the inner state of the person's criminal behavior. This is the subjective aspect of crime. Therefore, I believe that the arrangement of the object, the objective aspect, the subject and the subjective aspect of the constitution of crime is not disorderly, but is in line with people's rules of understanding and is an organic unity.

\subsection{The rationality of the theory of criminal constitution}

The comparative rationality of the theory of criminal constitution means that the theory of criminal constitution has comparative advantages and is more reasonable than other criminal identification theories. Since the current debate mainly focuses on whether to replace the theory of coupled crime formation with the progressive three-level criminal theory system of German-Japanese criminal law, it mainly focuses on comparing the criminal constitution theory with the three-level criminal theory system ${ }^{[5]}$.

\section{Basic Patterns of Chinese Criminal Law System and Analysis of Gains and Losses}

\subsection{The basic form of the Chinese criminal law system of crime-responsibility-crime}

The crime of determining the crime, determining the criminal responsibility of the offender and discriminating the offender should be subject to punishment. No matter which kind of criminal law system in the world, there are three central issues that cannot be avoided. However, in the German-Japanese criminal law system, through the three-level criminal theory system, the crime is determined and the offender's responsibility is determined. In the Chinese criminal law system, the task of determining the crime is based on the theory of crime. The crime theory of the center is completed and the determination of the criminal responsibility is completed by the theory of criminal responsibility. Therefore, the relatively independent criminal responsibility theory is a major feature of the Chinese criminal law system. How to determine the theoretical status of criminal responsibility has become a major issue in the scientific construction of the Chinese criminal law system. The central problem of the criminal law system is shown in Figure 2.

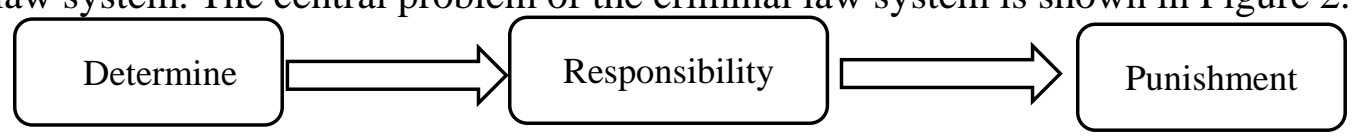

Figure 2 central problem of the criminal law system

\subsection{Analysis of the Success and Failure of Chinese Criminal Law System}

I have always believed that the Chinese criminal law system is basically scientific and 
reasonable. In the Chinese criminal law system, criminal theory determines whether an act is a crime based on the theory of criminal constitution and provides a basis for determining criminal responsibility; criminal responsibility is a bridge and bond between crime and punishment and the relationship between crime and punishment the role of regulation; the penalty theory determines how criminals who constitute criminal responsibility for crimes are punished. "The logical structure of sin-responsibility-crime is the epitome of the content of the whole criminal law.

\section{Conclusion}

Of course, the Chinese criminal law system is not perfect. I personally think that the current problems in the Chinese criminal law system mainly have the following two aspects: (1) China's criminal law system as a whole is more static and less dynamic. Identifying crimes, determining responsibilities and determining penalties are the complete process of criminal proceedings and three dynamic central tasks that criminal law needs to address. However, in the current criminal law system in China, the three dynamic processes are not sufficiently elaborated. The general chapters of criminal law textbooks such as the overall introduction of crime composition, the object of crime, the objective aspect of crime, the subject of crime, the subjective aspect of crime, until the unfinished form of crime, joint crimes, crimes, etc., are based on static description of crime, lacking Dynamically identify the relevant theoretical content of crime, attribution of responsibility and measurement of penalty. (2) In the three sections of criminal law system-crime theory, criminal responsibility theory and punishment theory_criminalism and punishment theory are relatively substantial, but the criminal liability theory is relatively blank and lacks substantive content. As a result, after an act is established, how to judge the size of its criminal responsibility lacks the standards and basis. In the criminal law system of our country, the criminal theory determines the crime based on the theory of criminal constitution, mainly based on the evaluation of the criminal behavior that has occurred. However, at some point, it may happen that an act constitutes a crime, but according to the subjective situation of the perpetrator, it is obviously inappropriate to impose severe punishment on it (such as the recent $\mathrm{Xu}$ Wei case). Under this circumstance, because the criminal responsibility theory lacks substantive judgment content, it does not function well as a bridge and bond between the criminal theory and the penalty theory, resulting in some special cases, according to our criminal law. The conclusions drawn by the academic system may not be consistent with the actual situation and the unification of legal effects and social effects cannot be achieved well.

\section{References}

[1]Sara Qayum,Sughra Farid,Suhail Shehzad,Weidong Zhu. Short Comings of Criminal Justice System of Pakistan and its Effects on the Rights of Accused Prisoner Wrongfully Convicted or Imprisoned [J]. Journal of Legal Studies, 2016, 18(32).

[2] Laurence Roy,Anne G. Crocker,Tonia L. Nicholls,Eric Latimer,Agnes Gozdzik,Patricia O'Campo,Jennifer Rae. Profiles of criminal justice system involvement of mentally ill homeless adults [J]. International Journal of Law and Psychiatry, 2016, 45.

[3] Wanle Chi,Xiaoyang Wang. Design of criminal analysis system based on OLAP [P]. Computer Science \&amp; Education (ICCSE), 2012 7th International Conference on, 2012.

[4] HAYASHI Hiromasa. 3. The present operational status and problems of the Saiban-in system from the viewpoint of Criminal Law (Symposium: The Saiban-in System (Lay Judge System))[J]. The Japanese Journal of Law and Political Science, 2010, 47(1).

[5] OHNO Masahiro. 2. The achievements and problems of the Saiban-in system from the viewpoint of Criminal Procedure Law (Symposium: The Saiban-in System (Lay Judge System))[J]. The Japanese Journal of Law and Political Science, 2010, 47(1). 